\title{
Mapeamento da distribuição espacial da cobertura vegetal no município de Ananindeua/PA
}

O objetivo deste trabalho foi analisar o comportamento da vegetação na localidade do município de Ananindeua - PA, através do índice de vegetação da diferença normalizada (NDVI) para a análise de geoprocessamento foi utilizado satélite Landsat 8 sensor OLI cena - 223/061 de 06/07/2017, sensor espectral OLI (Operation Land Imager) e termal TIRS (Thermallnfrared Sensor) disponibilizada pelo Instituto Nacional de Pesquisas Espaciais - INPE o datum de referência WGS 1984 (World Geodetic System) e no fuso $22 \mathrm{~S}$ os procedimentos foram realizados em ambiente SIG, utilizando o software ArcGis 10.5 . 0 produto obtido foi dividido em 6 intervalos de reflectância, pois essa quantidade de intervalos exibiu o melhor agrupamento das classes de acordo com a resposta espectral dos alvos, variado de 0,30 a 0,63 por pixel, o mapa de NDVI foi satisfatório para evidência a disposição da vegetação no município que sofre grande alteração pelo crescimento urbano ao logo da rodovia principal.

Palavras-chave: Vegetação; Impacto ambiental; Geotecnologia.

\section{Mapping of the spatial distribution of vegetation cover in the municipality of Ananindeua/PA}

The objective of this work was to analyze the vegetation behavior in the municipality of Ananindeua - PA, using the normalized difference vegetation index (NDVI) for the geoprocessing analysis. 07/2017, OLI spectral sensor (Operation Land Imager) and thermal TIRS (Thermallnfrared Sensor) made available by the National Institute for Space Research - INPE the reference datum WGS 1984 (World Geodetic System) and in the 22S spindle the procedures were performed in a GIS environment, using ArcGis 10.5 software. The product obtained was divided into 6 reflectance intervals, since this number of intervals exhibited the best grouping of classes according to the spectral response of the targets, ranging from -0.30 to 0.63 per pixel, the NDVI map was satisfactory for evidence the disposition of vegetation in the municipality that undergoes great change due to urban growth along the main highway.

Keywords: Vegetation; Environmental impact; Geotechnology.

Erick dos Santos Ribeiro

Universidade Federal Rural da Amazônia, Brasil http://lattes.cnpq.br/9915795223042598 ericksantos39@hotmail.com

\section{Sayure Mariana Raad (it}

Universidade Federal Rural da Amazônia, Brasil http://lattes.cnpq.br/8281827404307486 http://orcid.org/0000-0002-4127-7351 raadsayure@gmail.com

Rayanne de Jesus Castro (iD)

Universidade Federal Rural da Amazônia, Brasil http://lattes.cnpq.br/9088824012673103 http://orcid.org/0000-0001-7460-4390

castrorayanne60@gmail.com
Rafael Rodrigo da Silva Costa (iD

Universidade Federal Rural da Amazônia, Brasi http://lattes.cnpq.br/8564618234467361

http://orcid.org/0000-0002-5615-3466 rafaelrodrigo1992@hotmail.com

Glenda Tainara Santos Barbosa (iD)

Universidade Federal Rural da Amazônia, Brasil http://lattes.cnpq.br/3837721242386444 http://orcid.org/0000-0001-7603-0837 glendabarbosag@gmail.com

Francimary da Silva Carneiro (id)

Universidade Federal Rural da Amazônia, Brasil http://lattes.cnpq.br/8657235544233319

http://orcid.org/0000-0002-1693-8779

francimarycarneiro@gmail.com
Larissa Martins Barbosa D'Arace (iD

Universidade Federal Rural da Amazônia, Brasil http://lattes.cnpq.br/1315133297466306

http://orcid.org/0000-0002-8533-555X larissamartins350@gmail.com

\section{Mayra Piloni Maestri (iD)}

Universidade Federal Rural da Amazônia, Brasil http://lattes.cnpq.br/2687102042811310 http://orcid.org/0000-0002-8936-952X mayrapmaestri@hotmail.com 


\section{INTRODUÇÃO}

As questões voltadas ao entendimento do uso e cobertura do solo têm despertado forte interesse dentro e fora do meio científico. Isso tem ocorrido motivado pelo acelerado processo de mudança dos aspectos da superfície, que, por sua vez, associam-se aos diversos impactos ambientais e socioeconômicos oriundos, especialmente, dos processos antrópicos.

As vegetações possuem importante papel na estabilização do ambiente, pois protegem o solo dos processos erosivos e do intemperismo, influência nas condições climáticas e na infiltração e distribuição de água, com isso a vegetação exerce importante papel como indicador geoambiental, visto que esta influência diretamente nos fatores edafoclimáticos e bióticos (ALMEIDA et al., 2012).

A degradação ambiental é um dos problemas mais preocupantes na atualidade de decorrente principalmente pela retirada da vegetação, o estudo da dinâmica da cobertura vegetal tem papel primordial para a conscientização e responsabilidades sobre a consequências do processo de degradação ambiental, desta forma o índice de vegetação da diferença normalizada (NDVI- Normalized Difference Vegetation Index), surge como uma ferramenta de estudos de avaliação da dinâmica da cobertura vegetal e suas características voltadas ao comportamento espectral de alvos (SANTOS et al., 2005).

A densidade da vegetação na região do visível fornece uma menor refletância, devido à maior absorção de luz pelos pigmentos fotossintetizantes, porém a modelagem dos índices vegetação ocorre de forma contrária, fornecendo uma maior refletância devido ao maior adensamento e espalhamento nas diferentes camadas de folha (BORATTO et al., 2013).

Objetivo do presente trabalho foi analisar através do NDVI o comportamento da vegetação na localidade do município de Ananindeua - PA para interpretação da organização do espaço geográfico e modificações na cobertura vegetal diante do desenvolvimento da agricultura e crescimento urbano.

\section{METODOLOGIA}

Para processamento digital foi utilizado satélite Landsat 8, sensor OLI cena - 223/061 de 06/07/2017, sensor espectral OLI (Operation Land Imager) e termal TIRS (ThermalInfrared Sensor) disponibilizada pelo Instituto Nacional de Pesquisas Espaciais - INPE o datum de referência WGS 1984 (World Geodetic System) e no fuso $22 \mathrm{~S}$ os procedimentos foram realizados em ambiente SIG, utilizando o software ArcGis 10.5. O

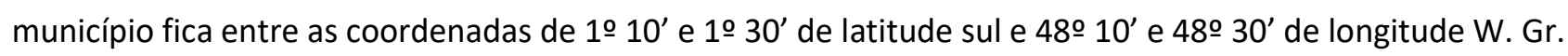

Sendo assim, O município localiza-se na latitude $01^{\circ} 21^{\prime}$ 5, tenho como ponto de referência o município de Ananindeua - PA que se estende por 190,5 km² e contava com 471980 habitantes no último censo. Para obtenção do mapa de localização foi realizado a composição da cor natural com as bandas 4, 3 e 2 para demonstração do território (Figura 1). 


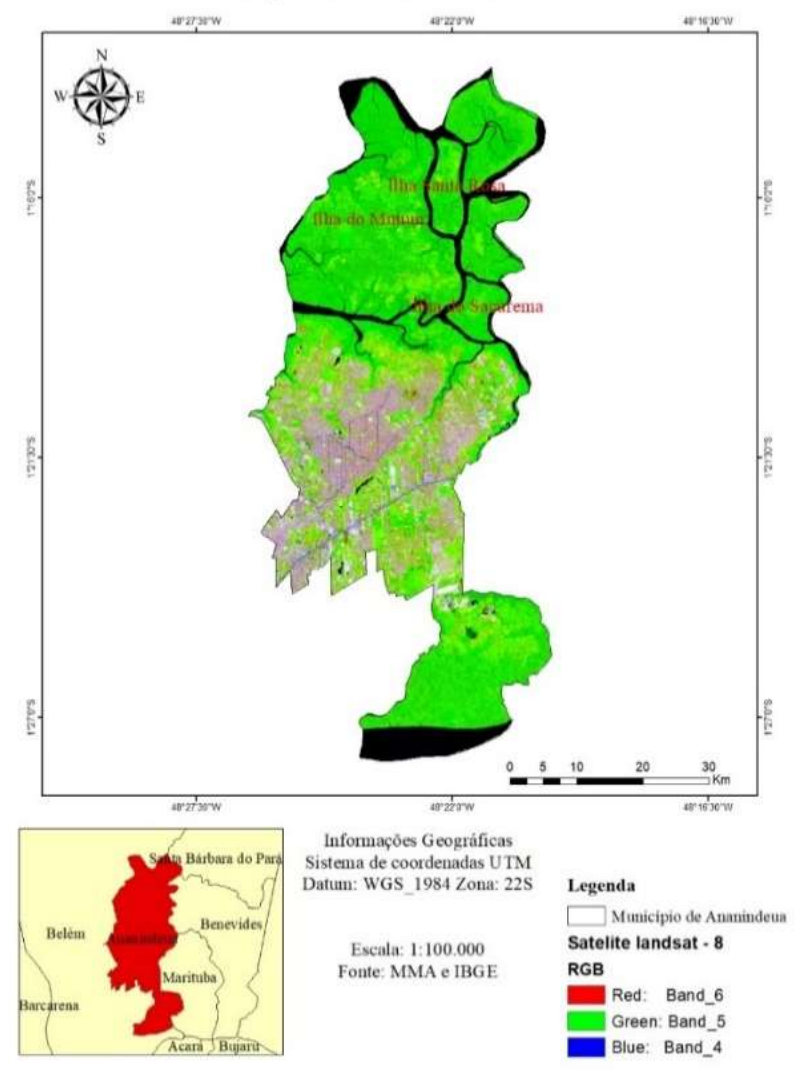

Figura 1: Mapa de localização do município de Ananindeua - PA.

Para realização do NDVI, foi aplicado o algoritmo (ROUSE et al., 1973) que consiste na diferença da refletância no infravermelho próximo e a refletância no vermelho dividido pela soma dessas duas bandas como mostra a seguinte equação:

$$
\mathrm{NDVI}=((R i v p-R v) /(R i v p+R v))
$$

$\mathrm{Na}$ etapa de análise para identificação das radiações espectrais que representam a energia solar refletida por cada pixel, por unidade de área, de tempo, do ângulo sólido e do comprimento de onda, medida nos sensores a bordo do satélite, que no caso do Landsat 8 sensor OLI, correspondem as medidas realizadas nos canais $1,2,3,4,5$ e 6 .

Para melhor observação das características peculiares do município referente a cobertura vegetal da área de estudo. Foi selecionada as bandas e clicado na opção NDVI para formação do mapa, surgido um raster com Tons de cinza que foi ajustado no guia para cores de 6 classes escolhidas (Quadro 1).

Quadro 1: Intervalos das respectivas classes e alvos de superfície do NDVI

\begin{tabular}{lll}
\hline NDVI & Classes & Alvos de superfície \\
\hline$-0,30--0,02$ & Classe 1 & Corpos d'água \\
\hline$-0,02-0,16$ & Classe 2 & Áreas sem Vegetação \\
\hline $0,16-0,26$ & Classe 3 & Vegetação Herbácea \\
\hline $0,26-0,37$ & Classe 4 & Vegetação ombrófila aberta \\
\hline $0,37-0,45$ & Classe 5 & Vegetação Ombrófila Densa \\
\hline $0,45-0,63$ & Classe 6 & Vegetação Ombrófila Densa Aluvial \\
\hline
\end{tabular}

Fonte: Barbosa et al. (2017). 
O produto obtido foi dividido em 6 intervalos de reflectância, pois essa quantidade de intervalos exibiu o melhor agrupamento das classes de acordo com a resposta espectral dos alvos, variado de $-0,30$ a 0,63 por pixel (Figura 2), de modo que quanto mais próximo de +1 , maior a densidade da vegetação sendo que a medida em que esse valor diminui, a vegetação vai ficando mais rala próxima de -1, maior indício de alteração na vegetação. Podendo está associada à saúde de organismos aclorofilados da região.

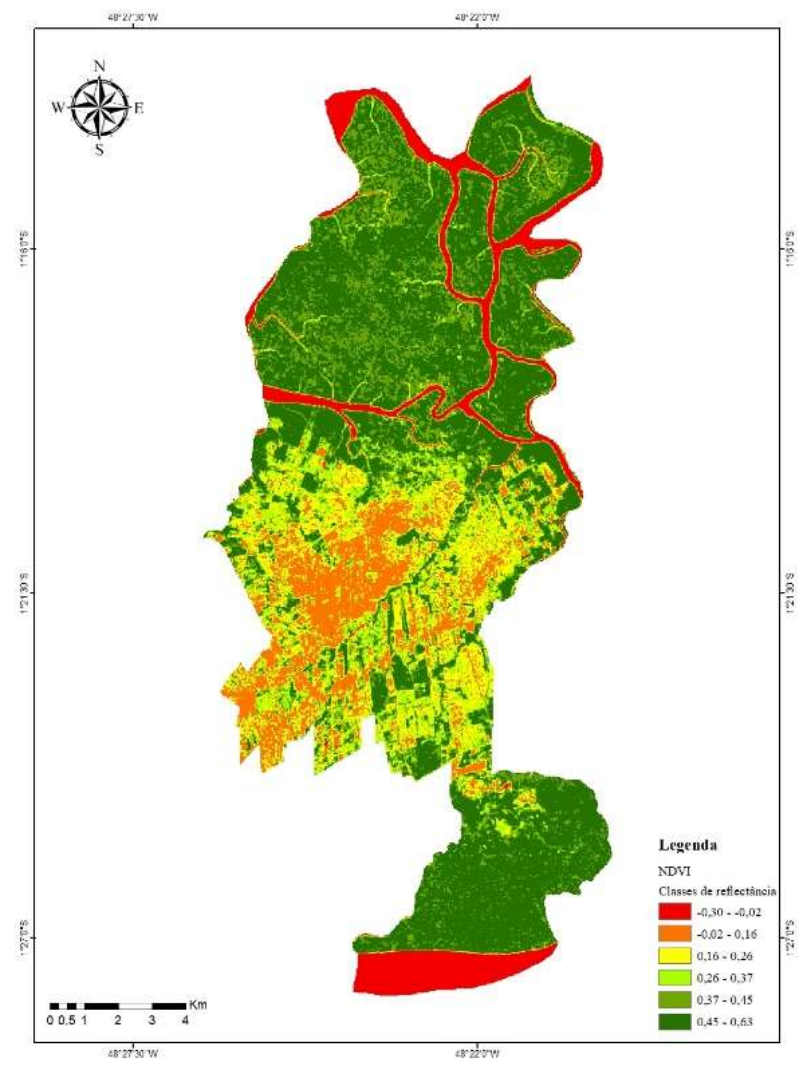

Figura 2: NDVI do município de Ananindeua - PA.

Com relação a classe de Áreas sem vegetação (uso antrópico) e sua definição, foram considerados os setores onde havia predominância de alvos com comportamentos espectrais característicos de áreas urbanas, bem como outras áreas onde houve supressão da cobertura vegetal e foram modificadas pelas ações humanas. Para tal constatação foi realizado um trabalho de campo que tiveram início no dia 14 de setembro e termino dia 01 de outubro de 2017, do centro da cidade para as áreas de vegetação remanescente com o intuito de observar a expressão da cobertura vegetação e a ocupação feita do município.

\section{RESULTADOS E DISCUSSÃO}

A partir do produto gerado, foi possível observar a diferença na distribuição na cobertura vegetal, os elementos visuais mais representativos são os de valores positivos, o que sugere a presença de cobertura vegetal, os valores de NDVI foram agrupados em 6 classes e seus respectivos alvos de superfície identificados em campo.

Os valores negativos representados na classe1 são corpos d'água que devido a sua característica físico química, com valores de $(-0,30--0,02)$, a maior parte do fluxo incidente sobre a água pura não é 
refletida, como ocorre no solo e na vegetação, mas sim absorvido ou transmitida. Nos comprimentos de onda do visível, pouca luz é absorvida, uma pequena quantidade é refletida e a maior parte é transmitida (MANTOVANI, 1993).

A classe 2 assim como a classe 1, é indicativa de superfícies sem vegetação. No entanto corresponde a locais com solos descobertos, rochas, áreas urbanizadas, estradas e outras áreas sem vegetação, com índices entre -0,02 - 0,16, interpretando pela cor laranja com grande extensão ao logo da região. Durante o trabalho de campo foi observado parte dessa alteração relacionada ação antrópica de remoção da vegetação pela implementação de edificações e surgimento de ocupação desordenada em centros de periferia (Figura 4).

Ao que concerne às classes vegetadas, a classe 3 estão agrupados os intervalos de valores positivos relacionados ao NDVI, variou de $(0,16-0,26)$. Vegetação de baixa atividade fotossintética, com alvos de superfície onde ocorrem a mistura espectral das áreas sem cobertura verde com áreas de vegetação herbácea associado a organismo de pequeno porte e caules não lenhosos ou flexíveis (figura 5). Presente em grande parte em terrenos baldios, canteiros de praças e edifícios.

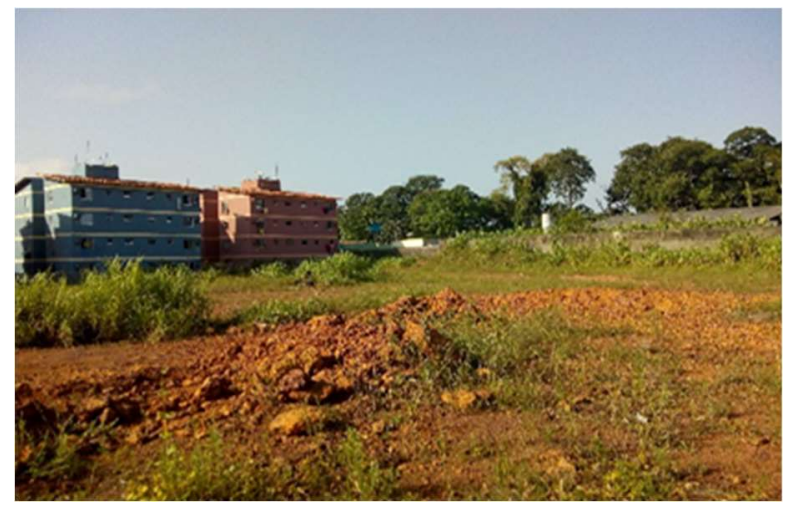

Figura 4: Ocupação urbana.

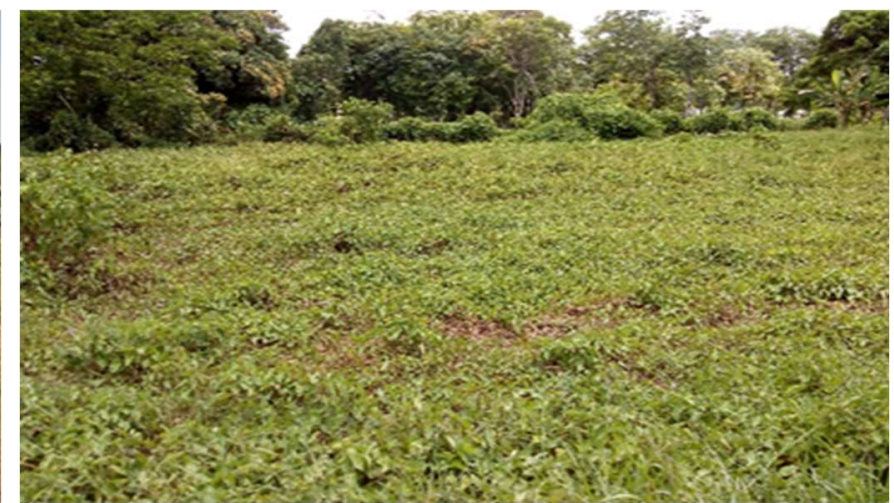

Figura 5: Vegetação herbácea.

No que se refere reflectância de classe 4 são agrupados entre $(0,26-0,37)$ com média atividade fotossintética, demonstra vegetação ombrófila aberta de crescimento espontâneo, de maior espaçamento entre as árvores com grande dispersão nos centros urbanos. Podendo representar locais de preservação árvores de uso paisagístico, ligadas à ornamentação de finalidade recreacional, localizada em parques e praças (Figura. 6). Assim como regiões de capoeira que sofreram alteração ao logo dos anos, para implantação de projetos de pavimentação e habitação.

Classe 5 são demonstradas grandes expressões de acordo com o mapa de NDVI valor, $(0,37-0,45)$ demonstrado floresta ombrófila densa com grande distribuição geoespacial vegetação verde de maior atividade fotossintética e densa, cujas folhas são mantidas durante todo o ano, mostrador vegetação remanescente que se mantem intacta com alto vigor ao logo dos anos, importante na preservação do ecossistema e ciclo da água (Figura 7). Na execução do NDVI em áreas urbanas na Amazônia, foi possível estimar de maneira visual a distribuição de vegetação densa na área urbana de Santarém de acordo com outros estudos desenvolvidos em regiões tropicais (TRINDADE et al., 2019). 


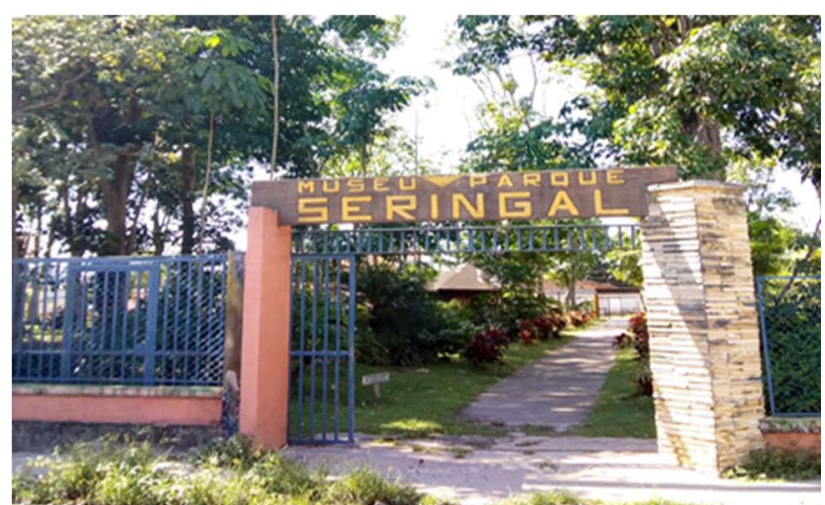

Figura 6: Vegetação ombrófila aberta.

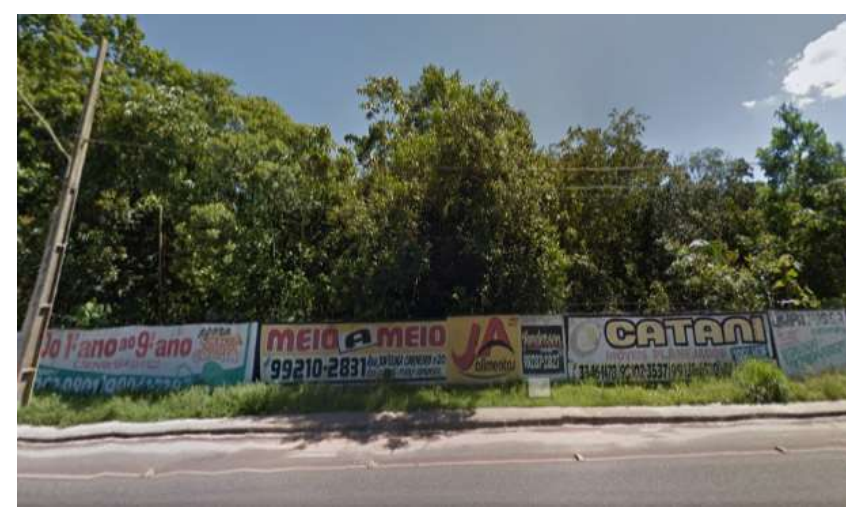

Figura 7: Vegetação ombrófila densa.

Na classe 6 localiza a vegetação ombrófila densa aluvial de máximo valor de 0,63 formação ribeirinha ou "floresta ciliar" que ocorre ao longo dos cursos de água, ocupando os terraços antigos das planícies quaternárias (Figura 8). Com máximo desempenho ao logo do rio maguari e nas ilhas Santa Rosa, Mutum e Sucurema.

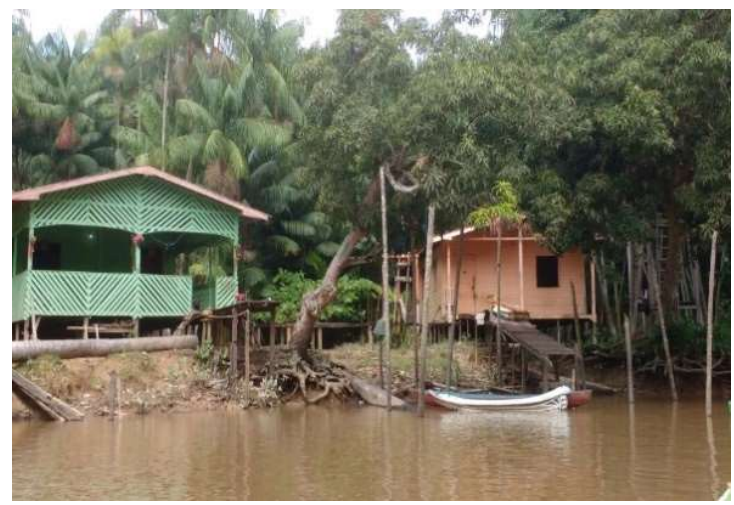

Figura 8: Comunidade da Ilha Sucurema.

Segundo Costa et al. (2016) concluíram que a região insular de Ananindeua se encontra em excelentes condições de preservação quanto a sua cobertura vegetal. Essa floresta é relevante para questões ambientais e socioeconômicas, como por exemplo, sua importância para o turismo local, a diversidade de espécies florestais no ambiente de várzea e as condições sociais das comunidades ribeirinhas. Em uma microbacia do riacho dos cavalos, Crateús-CE a vegetação foi diferenciada através do (NDVI), constatado que em áreas próximas aos açudes sofreram maior impacto com a supressão da cobertura vegetal pelas expansões das atividades agropecuárias (MELO, 2011). Em um mapeamento da distribuição da floresta remanescente no município de Santa Barbara/PA observou-se as mudanças nos diferentes estagio da vegetação que sofreu bruscas alterações pelas ações da agroindústria e exploração dos recursos naturais (RIBEIRO, 2020).

\section{CONCLUSÕES}

O mapa de NDVI foi satisfatório para evidência a disposição da vegetação no município que sofre grande alteração pelo crescimento urbano ao logo da rodovia principal. A região encontra-se em progressiva redução de cobertura vegetal, sendo necessário políticas de conservação da vegetação. 


\section{REFERÊNCIAS}

ALMEIDA, N. V.; CUNHA, S. B.; NASCIMENTO, F. R.. A cobertura vegetal e sua importância na análise morfodinâmica da bacia hidrográfica do Rio Taperoá Nordeste do Brasil/ Paraíba. Revista Geonorte, v.3, n.4, p.365-378, 2012.

BARBOSA, A. H. S.; CARVALHO, R. G.; CAMACHO, R. G. V.. Aplicação do NDVI para a Análise da Distribuição Espacial da Cobertura Vegetal na Região Serrana de Martins e Portalegre - Estado do Rio Grande do Norte. Revista do Departamento de Geografia, v.33, p.128-143, 2017.

BORATTO, I. M. P.; GOMIDE, R. L.. Aplicação dos índices de vegetação NDVI, SAVI e IAF na caracterização da cobertura vegetativa da região norte de Minas Gerais. In: SIMPÓSIO BRASILEIRO DE SENSORIAMENTO REMOTO - SBSR, 16. Anais. Foz do Iguaçu, 2013. p.7345-7352.

COSTA, A. M. S.; ROCHA, C. P.. Território, comunidade e uso e cobertura do solo na região insular do município de Ananindeua, estado do Pará. In: SEMINÁRIO INTERNACIONAL DE CIÊNCIAS DO MEIO AMBIENTE E SUSTENTABILIDADE NA AMAZÔNIA, 4; ENCONTRO AMAZÔNIA DA ASSOCIAÇÃO NACIONAL DE PÓSGRADUAÇÃO E PESQUISA EM AMBIENTE E SOCIEDADE, 1. Anais. 2016. p.1-8.

MANTOVANI, J. E.. Comportamento espectral da água: faixas espectrais de maior sensibilidade ao fitoplâncton na presença de matéria orgânica dissolvida e de matéria inorgânica particulada. São Jose dos Campos: INPE, 1993.
MELO, E. T.; SALES, M. C. L.; OLIVEIRA, J. G. B.. Aplicação do Índice de Vegetação por Diferença Normalizada (NDVI) para Análise da Degradação Ambiental da Microbacia Hidrográfica do Riacho dos Cavalos, Crateús-CE. Curitiba: UFPR, 2011.

RIBEIRO, E. S.; RAAD, S. M.; NASCIMENTO, R. S. C.; REIS, N. S.; FARO, B. L. S. O.; CANEIRO, F. S.; SANTOS, J. C.. Análise da Distribuição Espacial da Cobertura Vegetal no município de Santa Barbara/PA. Natural Resources, v.10, n.3, p.8-14, 2020.

ROUSE, J. W.; HAAS, R. H.; SCHELL, J. A.; DEERING, D. W. Monitoring vegetation systems in the Great Plains with ERTS. In: EARTH RESOURCES TECHNOLOGY SATELLITE-1 SYMPOSIUM, 3. Annals. Washington, 1973. p.309-317.

SANTOS, F. A.; OLIVEIRA, W. A. S.. Aplicação Do Índice De Vegetação Por Diferença Normalizada (NDVI) Para Avaliação Da Cobertura Vegetal Do Entorno Do Açude Caldeirão, Em Piripiri (PI), Brasil. Revista Equador, v.4, n.2, p.114-127, 2015.

TRINDADE, A. R.; DUTRA, V. A. B.; TAVARES, P. A.; SOUTO, J. I. O.; BELTRÃO, N. E. S.; RIBEIRO, H. M. C.. Aplicação de índices de vegetação para identificação de área construída e vegetação densa em áreas urbanas na Amazônia. In: SIMPÓSIO DE BRASILEIRO DE SENSORIAMENTO REMOTO, 19. Anais. Santos: INPE, 2019. p.1-4.

A CBPC - Companhia Brasileira de Produção Científica (CNPJ: 11.221.422/0001-03) detém os direitos materiais desta publicação. Os direitos referem-se à publicação do trabalho em qualquer parte do mundo, incluindo os direitos às renovações, expansões e disseminações da contribuição, bem como outros direitos subsidiários. Todos os trabalhos publicados eletronicamente poderão posteriormente ser publicados em coletâneas impressas sob coordenação da Sustenere Publishing, da Companhia Brasileira de Produção Científica e seus parceiros autorizados. Os (as) autores (as) preservam os direitos autorais, mas não têm permissão para a publicação da contribuição em outro meio, impresso ou digital, em português ou em tradução. 